\title{
On amplitudes of $P$ near the shadow zone
}

\author{
Inge Lehmann
}

Annali di Geofisica, Vol. 11, n. 3-4, 1958.

\begin{abstract}
51 short-period vertical North American and Canadian records of the Samoa earthquake 14 April 1957 were examined. Amplitudes of P were very large at the western stations $\left(\Delta<84^{\circ}\right)$ and small at the stations to the east, 8 of which recorded $\mathrm{P}$ at distances greater than $100^{\circ}$. There was a lack of stations at intermediate distances. At the greatest distance, $108^{\circ} .2$, the $\mathrm{P}$ waves were not diffracted waves, for the phase had the same general character as at shorter distances; the period was $2 \mathrm{sec}$. From $70^{\circ}$ to about $90^{\circ}$ the Samoa P timedistance curve is steeper than the JeffreysBullen curve. It had been found previously that from about $90^{\circ}$ epicentral distance onwards the variation ot the $\mathrm{P}$ amplitude with distance was not always the same and also that the shadow zone seemed to begin at different distances. It is suggested that this be due to small regional differences of velocity in the deepest layer $\mathrm{D}$ " of the mantle.
\end{abstract}

Some years ago I made a study [Lehmann 1953] in order to find out whether or not there was a sudden drop in the $P$ amplitude at $105^{\circ}$ or another neighbouring distance marking clearly the beginning of the shadow zone. I made use partly of the I.S.S. data and partly of Copenhagen records.

It is well known that $P$ is often recorded at distances greater than $105^{\circ}$, but usually it is small and it is considered to be a diffracted wave. I found, however, that in the I.S.S. there were sometimes series of $P$ entries up to $110^{\circ}$ or more the residuals of which were consistent enough to show that the onset was sharp and therefore not likely to be due to a diffracted wave. On the other hand I sometimes found that $P$ of an earthquake had considerable uncertainty already at distances of about $95^{\circ}$ or so and yet was recorded beyond $105^{\circ}$ as if no decrease of amplitude took place at that distance. Using Copenhagen records I found also that in some earthquakes $P$ was very clearly recorded up to and considerably beyond $105^{\circ}$ while in other earthquakes of similar magnitude $P$ became small and insignificant already at distances smaller than $100^{\circ}$. Thus the variation of amplitude with distance is different in different earthquakes. The shadow zone seems to begin at different distances and it is usually not possible to say exactly where it begins; there is no sudden decrease of amplitude to mark its boundary.

At the Lamont Geological Observatory the surface waves of the Sarno earthquake 14 April 1957 were being studied with the object of finding variations of phase velocity and hence of crustal thickness across the United States and Canada. 51 records of short-period vertical instruments had been collected. They were from epicentral distances ranging from $71^{\circ}$ to $114^{\circ}$. It was suggested to me by Dr. Ewing that I examine the records for the greatest distances in order to see how $P$ varied near the shadow zone.

It was immediately apparent that there was a considerable drop in amplitude from the nearer to the greatest epicentral distances, but it was clear also that no precise determination of the variation of amplitude with distance could be made, for the instruments varied and their response was not accurately known. Also, the distances are subject to errors, an epicentre in the Samoan region not being determinable with great precision. However, the two independent determinations of the U.S.C.G.S. and the Central Bureau at Strasbourg differed by less than $1^{\circ}$.

The seismological stations are not evenly distributed over the continent. There are a great many stations in the western part and they were at epicentral distances ranging from $71^{\circ}$ to $84^{\circ}$. There were 10 stations in the eastern part at distances greater than $100^{\circ}$ and there were not many stations in between.

$P$ amplitudes were very large at the western stations, the phase being marked by a group, or two groups, of large swings continuing for about a minute. The wave period was two seconds or a little less. Rapid City at an epicentral distance of $87^{\circ}$ still had very large amplitudes though somewhat smaller than the western stations. Fayetteville at $90^{\circ} .4$, however, had considerably smaller amplitudes though the phase was still quite large.

Columbia at distance $100^{\circ} .2$ was the nearest of the 10 stations at distances greater than $100^{\circ}$ and Halifax at $114^{\circ} .6$ the most distant. This station and Palisades at $106^{\circ} .9$ did not record $P$, but all the others did record it.

The Cleveland record from epicentral distance $101^{\circ} .3$ is shown in the figure. It is from a Sprengnether short-period vertical instrument. The $P$ amplitudes are here quite small as compared with those at the western stations. Where and how quickly the amplitudes fall off cannot be said because of a lack of stations at intermediate distances. The wave period 
is about $2 \mathrm{sec}$. as at the smaller distances.

The Kirkland Lake record from a distance of $103^{\circ} .4$ is almost exactly like the Cleveland record. The pattern is the same and the amplitudes are equal. It is also from a Sprengnether instrument. Chapel Hill at $102^{\circ} .2$ has similar amplitudes but the pattern is different; there is not the same division of the phase.

It is somewhat surprising to find that Shawinigan Falls at an epicentral distance of $108^{\circ} .2$ has a record similar to the Cleveland record and only slightly smaller. The pattern is the same and the waves have period of about $2 \mathrm{sec}$. The seismograph is a Willmore instrument and it may have greater magnification than the Sprengnether instrument in the period range in question, but that would be of no avail if the core boundary were grazed by the ray emerging at $105^{\circ}$. It is obvious that the path to Shawinigan Falls has the same general character as those to the nearer stations and that the waves recorded are not diffracted waves. The reason why the Cleveland record is shown and not the one from Shawinigan Falls is that the trace of the latter is a little fainter.

Of the other stations beyond $100^{\circ}$ Columbia at $100^{\circ} .2$ has a much smaller $P$ phase than the stations mentioned, but the pattern is the same. This is also true for Ottawa at $106^{\circ} .0$. Montreal at $107^{\circ} .5$ has quite a small but distinct $P$. State College at $103^{\circ} .9$ has also a clear but small $P$.

We have seen that the $P$ amplitudes are small in the $8^{\circ}$ range of distance $100^{\circ}$ to $108^{\circ}$. No precise determination of the variation of amplitude with distance can be made, not even for the distances of the many western stations, but the decrease of amplitude between $84^{\circ}$ and $100^{\circ}$ is very great, undoubtedly far greater than the decrease between $71^{\circ}$ and $84^{\circ}$. The strong decrease of amplitude will be due to a marked decrease of velocity gradient at depth. The lack of observations at intermediate distances makes it impossible to say whether the decrease is gradual or abrupt or to determine even roughly the depth at which it occurs. But our finding is in support of the assumption that K. E. Bullen's region $D$ divides itself into two regions of which the inner one, $D^{\prime \prime}$, is characterised by a velocity gradient that is very small and distinctly smaller than that of $D^{\prime}$ [Bullen 1956].

The fact that the time-curve straightens before the shadow zone is reached has led to this result. The JeffreysBullen $P$ curve straightens at about $90^{\circ}$ and has very little curvature from there onwards. The Samoa $P$ curve runs practically parallel to it at these distances.

It does not, however, run parallel to the J.-B. curve all the way from $70^{\circ}$ to $108^{\circ}$. Taking the time of occurrence of the earthquake to be $19: 17: 57$ as determined by the U.S.C.G.S. we find the following mean residuals:

$\begin{array}{rrr}70^{\circ}-75^{\circ} & 10 \text { observations } & 0^{\mathrm{s}} .96 \pm 0^{\mathrm{s}} .17 \\ 75^{\circ}-80^{\circ} & 8 \text { observations } & 1^{\mathrm{s}} .69 \pm 0^{\mathrm{s}} .11 \\ 100^{\circ}-108^{\circ} .2 & 8 \text { observations } & 2^{\mathrm{s}} .39 \pm 0^{\mathrm{s}} .17\end{array}$

There is some scatter of the residuals near $85^{\circ}$. Between $90^{\circ}$ and $100^{\circ}$ there are only 4 observations; the mean of their residuals is $2^{\mathrm{s}} .23 \pm 0^{\mathrm{s}} .22$. The azimuths of all the observing stations is between $30^{\circ}$ and $58^{\circ}$ so it is evident that the Samoa earthquake $P$ curve is steeper than the J.-B. curve from $70^{\circ}$ up to about $90^{\circ}$. The distances taken were geographic distances, but elipticity corrections were applied to the transmission times.

Since the amplitude of the direct $P$ wave usually is quite small at the greatest distances where it occurs it will not be easy to decide whether a $P$ phase as recorded is due to a direct or to a diffracted wave to find where the shadow zone begins. There is as a rule no short period waves in distant $P^{\prime} s$, and this has been taken to indicate diffraction. Whether it is a sure criterion it is not known and it is not applicable unless the recording instruments have a good response to short period waves. It does not seem to have been attempted to fix the beginning of the shadow zone of an individual earthquake by a method similar to the one applied here, by direct comparison of records. To obtain definite results it would be necessary to choose earthquakes well recorded at the distances in question by a dense network of stations as

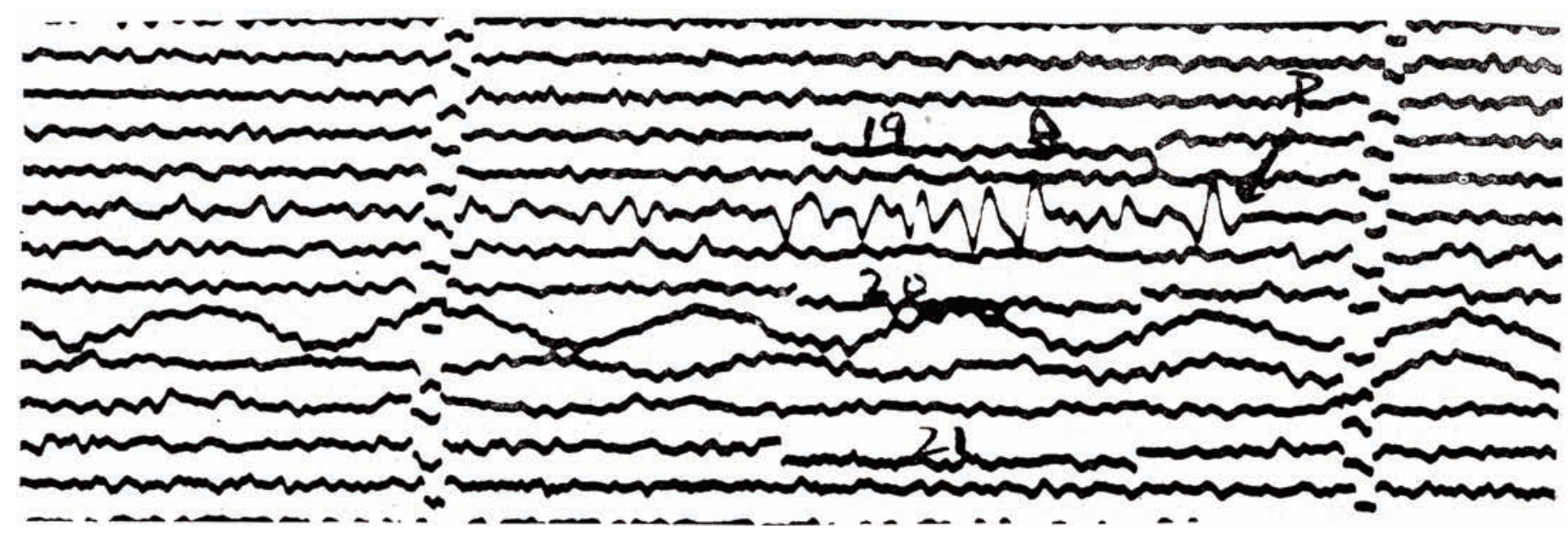

Samoa earthquake recorded at Cleveland, $\Delta=101^{\circ} .3$. 
e. g. that of western North America. Stations equipped with short period instruments would be required and it would be highly desirable that the relative response of the instruments as mounted should be known. This latter requirement is not easily fulfilled, but it may be indispensable if we are to succeed in deriving more detailed knowledge about the Earth's interior from seismological data.

Unless the error in the epicentre is unusually large, Shawinigan Falls is at an epicentral distance greater than $105^{\circ}$, and the shadow zone of our Samoan shock does not begin at this distance.

Taking the direct $P$ ray to reach out to different epicentral distances in different shocks, and the relative amplitudes to differ, we shall have to look for a possible explanation, and we find that slight regional variations in the composition of the region $D^{\prime \prime}$ would account for it. The velocity gradient in $D^{\prime \prime}$ is quite small and a small regional variation would alter slightly the curvature in $D^{\prime \prime}$ of the rays having their deepest points in the region. The rays are long and therefore a small bending or straightening of them in their deepest portion would give rise to an appreciable change in the epicentral distance at which they emerged. It would alter also the spreading of the rays and therefore affect amplitudes. Actually it is not known at present whether the difference in amplitude variation is regionally conditioned, but it would be of great interest to have it investigated.

Acknowledgements. Lamont Geological Observatory (Columbia University), Contribution No 319.

My thanks are due to Dr. Maurice Ewing by whose kind invitation I worked at the Lamont Geological Observatory and who allowed me to use the records of the Samoa earthquake collected there.

Since the preceding was written the study by A. Vogel, «Über Unregelmässigkeiten der äusseren Begrenzung des Erdkerns» (doctor's thesis, not printed) has become known to me. Observed regional variations in the transmission times of the waves reflected at the core boundary are put down to irregularities in this boundary.

Undulations in the core boundary would account also for the shadow zone for $P$ beginning at different epicentral distances in different earthquakes, but not for the observed differences in amplitude variation. They seem to require for their explanation the (additional) assumption of regional variation of velocity in $D^{\prime \prime}$.

\section{References}

Bullen, K.E. (1956). Seismology and the broad structure of the Earth's interior, Phys. Chem. Earth, 1, 68-93. Lehmann, I. (1953). On the shadow of the Earth's core, Bull. Seismol. Soc. Amer., 43, 291-306.

(C) 2010 by the Istituto Nazionale di Geofisica e Vulcanologia. All rights reserved. 